\title{
Exogenous Lipoid Pneumonia Successfully Treated With Bronchoscopic Segmental Lavage Therapy
}

\author{
Shota Nakashima MD, Yuji Ishimatsu MD PhD, Shintaro Hara MD PhD, \\ Masanori Kitaichi MD PhD, and Shigeru Kohno MD PhD
}

\begin{abstract}
A 65-y-old Japanese man was referred to the respiratory medicine department because of abnormal radiologic findings. High-resolution chest computed tomography scans revealed a geographic distribution of ground-glass opacities and associated thickening of the interlobular septa (crazy-paving patterns) in both lower lobes. He had a habit of drinking $400-500 \mathrm{~mL}$ of milk and $400-800 \mathrm{~mL}$ of canned coffee with milk every day. A swallowing function test revealed liquid dysphagia. Bronchoalveolar lavage fluid cytology findings showed multiple lipid-laden macrophages. Taken together, these findings revealed exogenous lipoid pneumonia. We performed bronchoscopic segmental lavage therapy 3 times in the left lung. After the treatment, the radiologic findings improved in both lungs. The patient has not experienced a recurrence of lipoid pneumonia in 2 y to date. In conclusion, a case of exogenous lipoid pneumonia was successfully treated with bronchoscopic segmental lavage therapy. Key words: lipoid pneumonia; exogenous lipoid pneumonia; treatment; milk; bronchoscopic segmental lavage; multiple segmental bronchoalveolar lavages. [Respir Care 2015;60(1):e1-e5. (C) 2015 Daedalus Enterprises]
\end{abstract}

\section{Introduction}

Exogenous lipoid pneumonia is an uncommon form of pneumonia that is related to the inhalation or aspiration of fatty substances. ${ }^{1}$ Although there are reports of lipoid pneumonia being successfully treated with corticosteroids, ${ }^{2-4}$ immunoglobulins, ${ }^{5}$ and whole-lung lavage, ${ }^{6-10}$ treatment of lipoid pneumonia is not well studied, and the published literature consists only of case reports. We report a case of exogenous lipoid pneumonia successfully treated with bronchoscopic segmental lavage therapy.

Drs Nakashima, Ishimatsu, Hara, and Kohno are affiliated with the Second Department of Internal Medicine, Nagasaki University School of Medicine, Nagasaki, Japan. Dr Kitaichi is affiliated with the Department of Pathology, National Hospital Organization, Kinki-Chuo Chest Medical Center, Osaka, Japan.

The authors have disclosed no conflicts of interest.

Correspondence: Yuji Ishimatsu MD PhD, Second Department of Internal Medicine, Nagasaki University School of Medicine, 1-7-1 Sakamoto, Nagasaki 852-8501, Japan. E-mail: yuji-i@nagasaki-u.ac.jp.

DOI: $10.4187 /$ respcare. 03225

\section{Case Report}

A 65-y-old Japanese man was referred to the respiratory medicine department at our hospital because of abnormal radiologic findings. He had undergone a left hepatic lobectomy 13 y prior because of hepatocellular carcinoma. The patient had no respiratory symptoms. He reported a cigarette smoking habit of 1 pack/d for $45 \mathrm{y}$, and surprisingly, he had a habit of drinking $400-500 \mathrm{~mL}$ of milk and $400-800 \mathrm{~mL}$ of canned coffee with milk every day. His oxygen saturation was $96 \%$ on room air, and his body temperature was $35.6^{\circ} \mathrm{C}$. His respiratory sounds were nor$\mathrm{mal}$, and leg edema was not observed. An arterial blood gas analysis on room air revealed a $\mathrm{pH}$ of $7.43, \mathrm{P}_{\mathrm{aO}_{2}}$ or $82.5 \mathrm{~mm} \mathrm{Hg}$, and $\mathrm{P}_{\mathrm{aCO}}$ of $36.5 \mathrm{~mm} \mathrm{Hg}$. His white blood cell count was $9.9 \times 10^{3}$ cells $/ \mu \mathrm{L}, \mathrm{C}$-reactive protein was $1.6 \mathrm{mg} / \mathrm{dL}$, and the levels of serum Krebs von den Lungen-6 (KL-6) were elevated $(1,255 \mathrm{U} / \mathrm{mL})$. Pulmonary function tests demonstrated diffusion impairment as follows: vital capacity, $106.2 \%$ of predicted; $\mathrm{FEV}_{1}, 98.1 \%$ of predicted; diffusing capacity of the lung for carbon monoxide, $74.3 \%$ of predicted; and diffusing capacity/alveolar volume, $58.5 \%$ of predicted. The laboratory data and pulmonary function tests are shown in Table 1 . Chest radiography revealed bilateral reticular shadows in both the mid 
Table 1. Laboratory Data and Pulmonary Function Tests on Admission

\begin{tabular}{|c|c|}
\hline & Values \\
\hline \multicolumn{2}{|l|}{ Hematology } \\
\hline White blood cells $\left(\times 10^{3}\right.$ cells $\left./ \mu \mathrm{L}\right)$ & 9.9 \\
\hline Red blood cells $\left(\times 10^{6}\right.$ cells $\left./ / \mu \mathrm{L}\right)$ & 4.92 \\
\hline Hemoglobin $(\mathrm{g} / \mathrm{dL})$ & 14.8 \\
\hline Hematocrit $(\%)$ & 44.8 \\
\hline Platelets $\left(\times 10^{4}\right.$ cells $\left./ \mu \mathrm{L}\right)$ & 25.2 \\
\hline \multicolumn{2}{|l|}{ Arterial blood gas analysis (room air) } \\
\hline $\mathrm{pH}$ & 7.43 \\
\hline $\mathrm{P}_{\mathrm{aCO}_{2}}(\mathrm{~mm} \mathrm{Hg})$ & 36.7 \\
\hline $\mathrm{P}_{\mathrm{aO}_{2}}(\mathrm{~mm} \mathrm{Hg})$ & 94.8 \\
\hline $\mathrm{HCO}_{3}^{-}(\mathrm{mmol} / \mathrm{L})$ & 23.9 \\
\hline \multicolumn{2}{|l|}{ Biochemistry } \\
\hline Total protein $(\mathrm{g} / \mathrm{dL})$ & 6.8 \\
\hline Albumin $(\mathrm{g} / \mathrm{dL})$ & 3.8 \\
\hline Total bilirubin $(\mathrm{mg} / \mathrm{dL})$ & 0.5 \\
\hline Aspartate aminotransferase (U/L) & 16 \\
\hline Alanine aminotransferase (U/L) & 22 \\
\hline Lactate dehydrogenase (U/L) & 154 \\
\hline Alkaline phosphatase (U/L) & 279 \\
\hline Blood urea nitrogen (mg/dL) & 12 \\
\hline Creatinine $(\mathrm{mg} / \mathrm{dL})$ & 0.84 \\
\hline Sodium $(\mathrm{mEq} / \mathrm{L})$ & 139 \\
\hline Potassium (mEq/L) & 5.2 \\
\hline Chlorine $(\mathrm{mEq} / \mathrm{L})$ & 105 \\
\hline Total cholesterol (mg/dL) & 194 \\
\hline Triglycerides (mg/dL) & 100 \\
\hline \multicolumn{2}{|l|}{ Serology } \\
\hline C-reactive protein $(\mathrm{mg} / \mathrm{dL})$ & 1.63 \\
\hline KL-6 (U/mL) & 1,255 \\
\hline Surfactant protein D (ng/mL) & 99.2 \\
\hline Surfactant protein A $(\mathrm{ng} / \mathrm{mL})$ & 78.5 \\
\hline Antinuclear antibody & - \\
\hline Soluble interleukin-2 receptor (U/mL) & 856 \\
\hline Angiotensin-converting enzyme (U/L) & 15.6 \\
\hline \multicolumn{2}{|l|}{ Pulmonary function tests } \\
\hline Vital capacity $(\mathrm{L})$ & 3.61 \\
\hline Vital capacity (\% of predicted) & 106.2 \\
\hline $\mathrm{FEV}_{1}(\mathrm{~L})$ & 2.56 \\
\hline $\mathrm{FEV}_{1}(\%$ of predicted $)$ & 98.1 \\
\hline $\mathrm{D}_{\mathrm{LCO}}(\%$ of predicted $)$ & 74.3 \\
\hline $\mathrm{D}_{\mathrm{LCO}}$ /alveolar volume (\% of predicted) & 58.5 \\
\hline \multicolumn{2}{|l|}{ 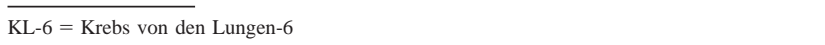 } \\
\hline
\end{tabular}

and lower fields (Fig. 1A). High-resolution chest computed tomography scans revealed a geographic distribution of ground-glass opacities and associated thickening of the interlobular septa (crazy-paving patterns) in both lower lobes (Fig. 1, B and C). An examination of bronchoalveolar lavage fluid (BALF) from the left B8 bronchus showed a normal total cell count $\left(2.5 \times 10^{5}\right.$ cells $\left./ \mathrm{mL}\right)$, including $67 \%$ macrophages, $20 \%$ lymphocytes, $3 \%$ neutrophils, and

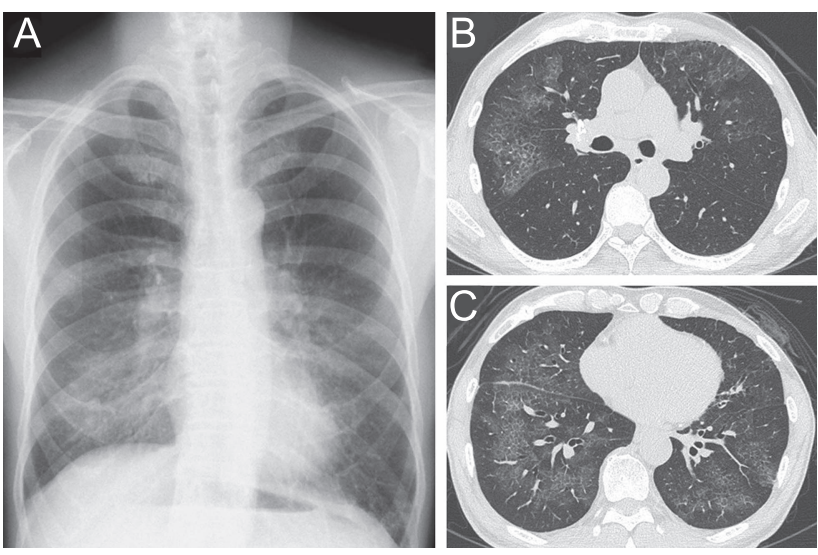

Fig. 1. A: Chest radiography revealed bilateral reticular shadows in both mid and lower lung fields. B and C: High-resolution chest computed tomography scans revealed a geographic distribution of ground-glass opacities and associated thickening of the interlobular septa (crazy-paving patterns) in both lower lobes.

Table 2. Bronchoalveolar Lavage Fluid Findings

\begin{tabular}{lr}
\hline \hline & Values \\
\hline Total cells $\left(\times 10^{5} / \mathrm{mL}\right)$ & 2.5 \\
Macrophages $(\%)$ & 67.3 \\
Neutrophils (\%) & 3.2 \\
Lymphocytes $(\%)$ & 20.4 \\
Eosinophils (\%) & 9.1 \\
CD4/CD8 ratio & 2.1 \\
\hline
\end{tabular}
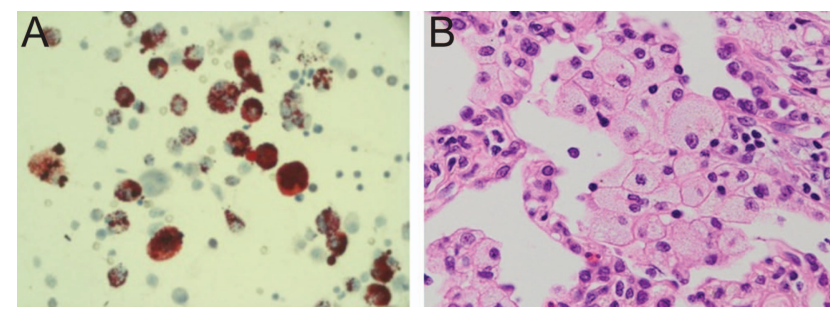

Fig. 2. A: Bronchoalveolar lavage fluid cytology showed multiple lipid-laden macrophages (Oil Red O staining). B: Lung specimens obtained by surgical lung biopsy showed airway-centered inflammatory lesions with foamy macrophages in the terminal air spaces (hematoxylin and eosin stain).

$9 \%$ eosinophils. The CD4/CD8 ratio of lymphocyte subsets was 2.1. The BALF findings are shown in Table 2. The BALF appeared colorless and transparent and did not show a milky appearance. Cultures of the BALF were negative for bacterial, fungal, and mycobacterial pathogens. The BALF cytologic findings showed multiple lipidladen macrophages (Oil Red O staining) (Fig. 2A). Lung specimens of the right B4 and B8 bronchi obtained by surgical lung biopsy showed airway-centered inflammatory lesions with foamy macrophages in the terminal air spaces (Fig. 2B). A swallowing function test revealed liq- 


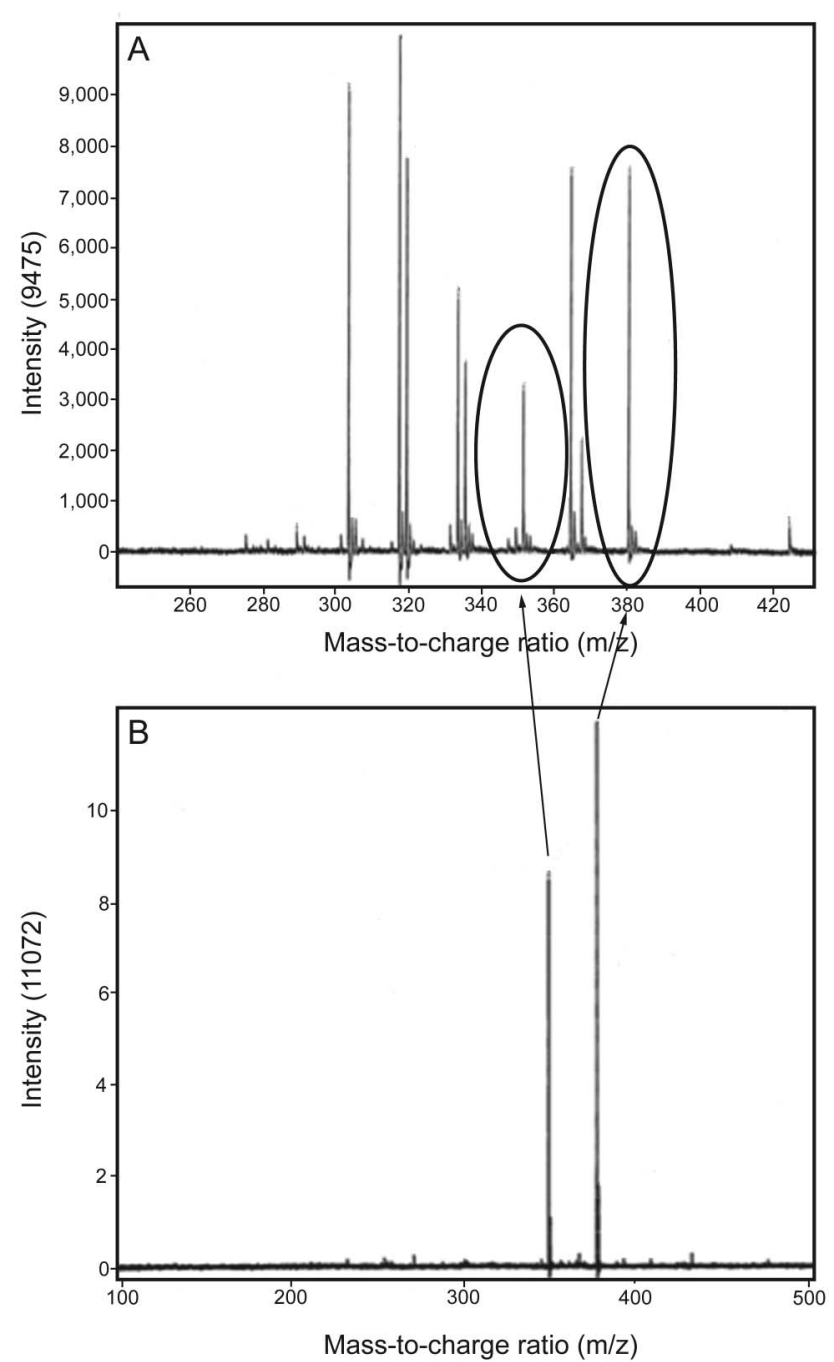

Fig. 3. Electrospray ionization mass spectrometry analysis of the bronchoalveolar lavage fluid (BALF) pellet and milk at intensity 9,475 (A) and intensity 11,072 (B). Two specific peaks were observed in both the BALF pellet and milk (arrows and circles) that were not observed in BALF pellets of normal volunteers (data not shown). It was believed that these peaks resulted from monoglycerides produced in the triglycerides' resolution processes from their molecular weights.

uid dysphagia. Taken together, these findings revealed exogenous lipoid pneumonia.

In addition, we performed an electrospray ionization mass spectrometry analysis of the BALF pellet and milk. Two specific peaks were observed in both the BALF pellet and milk samples (Fig. 3, arrows and circles), which were not observed in BALF pellets of normal volunteers (data not shown). It was believed that these peaks were caused by monoglycerides produced in the triglycerides' resolution processes from their molecular weights. These findings indicated the possibility of milk-induced or milk-containing drink-induced exogenous lipoid pneumonia.
This case received a follow-up examination because the patient had no respiratory symptoms. However, high-resolution computed tomography scans revealed extension of the ground-glass opacities and partial fibrosis after 10 months. Serum KL-6 levels were also elevated (2,300 $\mathrm{U} / \mathrm{mL}$ ). Pulmonary function tests revealed no remarkable changes. We performed bronchoscopic segmental lavage therapy 3 times in $15 \mathrm{~d}$ in the left lung, where radiologic findings had increased remarkably. For therapeutic purposes, $250-, 400-$, and $250-\mathrm{mL}$ volumes of warmed $\left(37^{\circ} \mathrm{C}\right)$ sterile saline were instilled, and the recovery rates were $57 \%, 42 \%$, and $76 \%$, respectively. Chest percussion was not performed. The patient was given oral amoxicillin for a short duration to prevent infection after the bronchoscopy. He did not receive steroid therapy. We instructed the patient not to drink milk or milk-containing drinks at discharge.

Three months after the treatment, serum KL-6 levels decreased from 2,300 to $1,296 \mathrm{U} / \mathrm{mL}$, and the radiologic findings improved in both lungs, including the right lung, where therapeutic BAL was not performed (Fig. 4). The patient has not experienced a recurrence of lipoid pneumonia in $2 \mathrm{y}$ to date.

\section{Discussion}

Exogenous lipoid pneumonia is an uncommon form of pneumonia related to the inhalation or aspiration of fatty substances. ${ }^{1}$ In adults, most cases result from the use of oil-based laxatives for the treatment of constipation, followed by the nasal instillation of oily products for chronic rhinopharyngeal diseases. ${ }^{11}$ Other less commonly reported causes of lipoid pneumonia include the aspiration of milk. The diagnosis of exogenous lipoid pneumonia is based on a history of exposure to oil with radiologic findings consistent with the disease and the presence of lipid-laden macrophages in sputum or BAL analyses. ${ }^{12}$ The patient was diagnosed with exogenous lipoid pneumonia, as BALF cytology showed multiple lipid-laden macrophages.

Betancourt et $\mathrm{al}^{13}$ reported that exogenous lipoid pneumonia is classified into acute and chronic forms. Acute exogenous lipoid pneumonia is uncommon and typically caused by an episode of aspiration of a large quantity of a petroleum-based product. Chronic exogenous lipoid pneumonia usually results from repeated episodes of aspiration or the inhalation of fatty substances over an extended period. ${ }^{13}$

The patient had a habit of consuming large quantities of milk and canned coffee with milk every day. Taken together, his habits, liquid dysphagia, and the specific peaks observed for both the BALF pellet and milk on electrospray ionization mass spectrometry indicated the possibility of milk-induced or milk-containing drink-induced chronic exogenous lipoid pneumonia. 


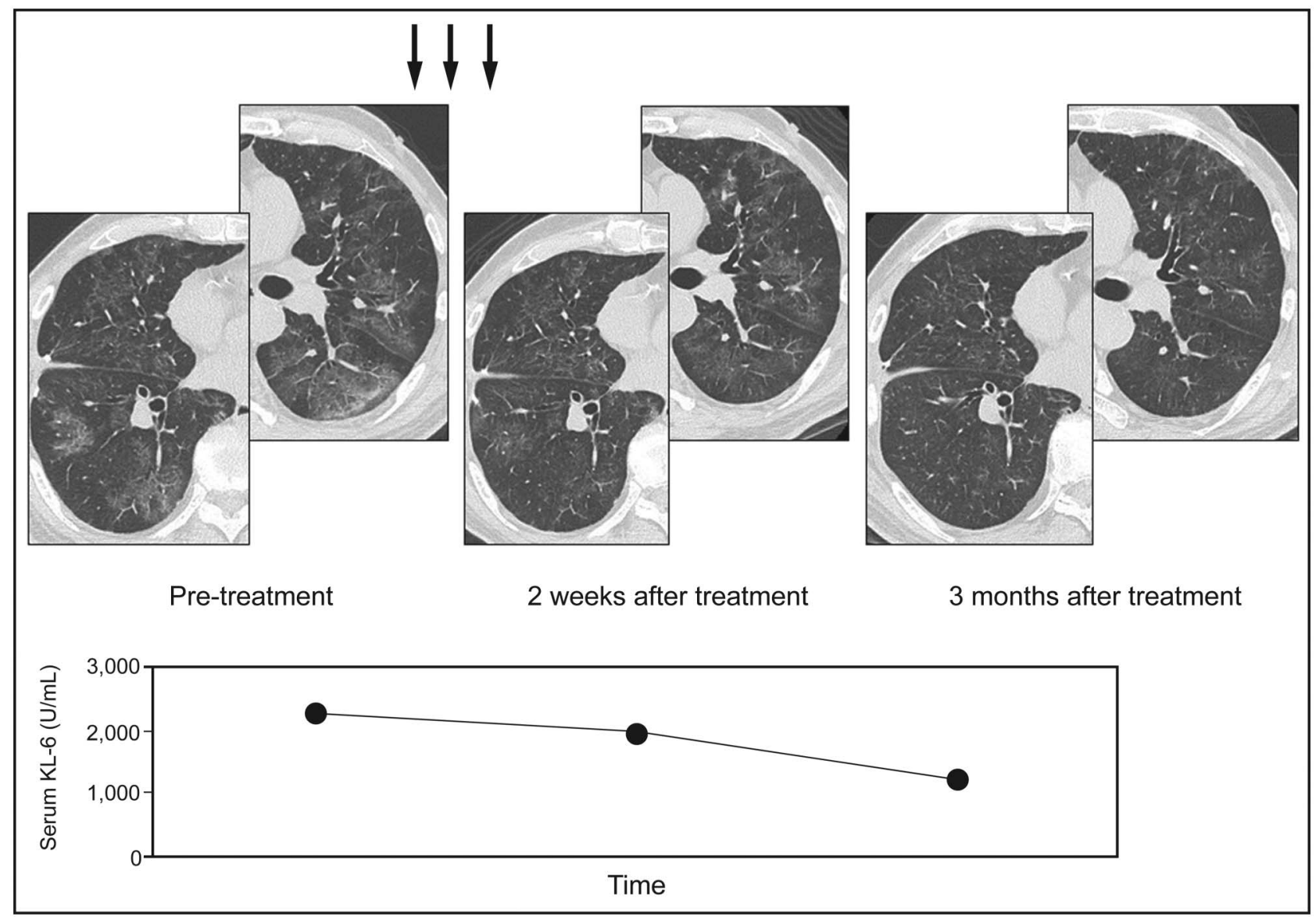

Fig. 4. We performed bronchoscopic segmental lavage therapy 3 times in $15 \mathrm{~d}$ in the left lung, where the radiologic findings had increased remarkably. For therapeutic purposes, $250-, 400-$, and $250-\mathrm{mL}$ volumes of warmed $\left(37^{\circ} \mathrm{C}\right)$ sterile saline were instilled. After the treatment (arrows), the levels of serum Krebs von den Lungen-6 (KL-6) decreased, and the radiologic findings improved in both lungs.

Treatment of lipoid pneumonia is not well studied, and the published literature contains only case reports. In cases of exogenous lipoid pneumonia, avoiding ongoing exposure and providing supportive care are the mainstays of treatment. ${ }^{1}$ There are reports of lipoid pneumonia successfully treated with corticosteroids, ${ }^{2-4}$ immunoglobulins, ${ }^{5}$ and whole-lung lavage. ${ }^{6-10}$ Pulmonary alveolar proteinosis can by treated with multiple segmental or lobar lavages by fiberoptic bronchoscopy using local anesthesia, which could be an alternative to a whole-lung lavage in patients with mild cases of pulmonary alveolar proteinosis. ${ }^{14} \mathrm{We}$ chose this treatment because we thought that an immunosuppressive agent should be avoided because he suffered from hepatitis B virus infection. In addition, the patient showed a slight radiologic improvement after diagnostic BAL. We performed therapeutic BAL 3 times in the left lung, where the radiologic findings had increased remarkably. After undergoing multiple segmental lavages, the patient showed radiologic improvements in both lungs, including the right lung, in which normal saline solution was not instilled. These findings may indicate that seg- mental lavage therapy not only washes away lipids directly but also improves lung opacities by other mechanisms. However, the mechanisms are unclear. Hypoxemia during lavage was slight, and a lower respiratory tract infection did not occur. However, we should note that this treatment may not be effective for patients with advanced cases of exogenous lipoid pneumonia.

In conclusion, exogenous lipoid pneumonia was successfully treated with multiple bronchoscopic segmental lavages. Bronchoscopic segmental lavage therapy could be a therapeutic option for exogenous lipoid pneumonia.

\section{ACKNOWLEDGMENTS}

We thank Naoya Kishikawa MSc, Mohamed Saleh Elgawish MSc, and Naotaka Kuroda MSc (Graduate School of Biomedical Sciences, Course of Pharmaceutical Sciences, Nagasaki University, Nagasaki, Japan) for performing the electrospray ionization mass spectrometry analyses. Editage provided editorial assistance.

\section{REFERENCES}

1. Hadda V, Khilnani GC. Lipoid pneumonia: an overview. Expert Rev Respir Med 2010;4(6):799-807. 


\section{Exogenous Lipoid Pneumonia Treated With Bronchoscopic Segmental Lavage Therapy}

2. Lococo F, Cesario A, Porziella V, Mulè A, Petrone G, Margaritora $\mathrm{S}$, Granone P. Idiopathic lipoid pneumonia successfully treated with prednisolone. Heart Lung 2012;41(2):184-187.

3. Hadda V, Khilnani GC, Bhalla AS, Mathur S. Lipoid pneumonia presenting as non resolving community acquired pneumonia: a case report. Cases J 2009;2:9332.

4. Chin NK, Hui KP, Sinniah R, Chan TB. Idiopathic lipoid pneumonia in an adult treated with prednisolone. Chest 1994;105(3):956-957.

5. Amato GM, Novara V, Amato G. [Lipid pneumonia. Favorable outcome after treatment with intravenous immunoglobulins, steroids, cephalosporins]. Minerva Pediatr 1997;49(4):163-169.

6. Sias SM, Ferreira AS, Daltro PA, Caetano RL, Moreira Jda S, QuiricoSantos T. Evolution of exogenous lipoid pneumonia in children: clinical aspects, radiological aspects and the role of bronchoalveolar lavage. J Bras Pneumol 2009;35(9):839-845.

7. Sias SM, Daltro PA, Marchiori E, Ferreira AS, Caetano RL, Silva CS, et al. Clinic and radiological improvement of lipoid pneumonia with multiple bronchoalveolar lavages. Pediatr Pulmonol 2009;44(4): 309-315.

8. Ciravegna B, Sacco O, Moroni C, Silvestri M, Pallecchi A, Loy A, Rossi GA. Mineral oil lipoid pneumonia in a child with anoxic encephalopathy: treatment by whole lung lavage. Pediatr Pulmonol 1997;23(3):233-237.

9. Wong CA, Wilsher ML. Treatment of exogenous lipoid pneumonia by whole lung lavage. Aust N Z J Med 1994;24(6):734-735.

10. Chang HY, Chen CW, Chen CY, Hsuie TR, Chen CR, Lei WW, et al. Successful treatment of diffuse lipoid pneumonitis with whole lung lavage. Thorax 1993;48(9):947-948.

11. Gondouin A, Manzoni P, Ranfaing E, Brun J, Cadranel J, Sadoun D, et al. Exogenous lipid pneumonia: a retrospective multicentre study of 44 cases in France. Eur Respir J 1996;9(7):1463-1469.

12. Marchiori E, Zanetti G, Mano CM, Hochhegger B. Exogenous lipoid pneumonia. Clinical and radiological manifestations. Respir Med 2011;105(5):659-666.

13. Betancourt SL, Martinez-Jimenez S, Rossi SE, Truong MT, Carrillo J, Erasmus JJ. Lipoid pneumonia: spectrum of clinical and radiologic manifestations. AJR Am J Roentgenol 2010;194(1): 103-109.

14. Cheng SL, Chang HT, Lau HP, Lee LN, Yang PC. Pulmonary alveolar proteinosis: treatment by bronchofiberscopic lobar lavage. Chest 2002;122(4):1480-1485 